\title{
EL PROCEDIMIENTO DE ASILO ANTE LA PERSECUCIÓN DE PANDILLAS*
}

\author{
THE ASYLUM PROCEDURE IN THE FACE OF PERSECUTION BY ARMED BANDS
}

\author{
Ivana Belén Ruiz-Estramil ${ }^{1}$ \\ Universidad del País Vasco
}

Fecha de recepción: 16 de agosto de 2018; Fecha de aceptación: 8 de noviembre de 2018; Publicado online: 28 mayo de 2019

Cómo citar este artículo / Citation: Ruiz-Estramil, Ivana Belén. 2019. «El procedimiento de asilo ante la persecución de pandillas». Disparidades 74(1): e012. doi: <https://doi.org/10.3989/dra.2019.01.012>.

RESUMEN: Este artículo aborda las dificultades en el acceso al asilo en el Estado español de aquellos sujetos que sufren persecución por parte de pandillas en Centroamérica. Bajo la consideración de una migración causada por delincuencia común y no fruto de una persecución y desprotección del Estado, la posibilidad de acceso al asilo se reduce hasta el punto de no optar a una protección internacional. Se ahonda en este escrito en la consideración de desprotección que se estipula en la Convención de Ginebra así como en el Protocolo de Nueva York, aterrizando en la casuística del procedimiento de asilo español y analizando la manera en la que se está razonando la negativa al acceso a protección en estos casos concretos. Se recoge por tanto una reflexión en torno a las nuevas formas de desprotección que desde el derecho de refugiados deberá trabajarse e incorporar.

PALABRAS CLAVE: Asilo; Bandas armadas; Protección internacional; Refugiado; Reconocimiento.

ABSTRACT: This article addresses the difficulties accessing asylum in the Spanish State of those individuals who suffer persecution by gangs in Central America. Because the cause of this kind of migration is considered to be common crime, and not persecution and lack of protection from the State, access to asylum is reduced to the point of not receiving international protection. This paper examines the consideration of lack of protection stipulated in the Geneva Convention as well as in the New York Protocol, concluding with the casuistry of the Spanish asylum procedure, analysing the way in which refusal to grant access to protection is being reasoned in these specific cases. It also includes a consideration about the new forms of lack of protection that Refugee Law should work on and incorporate.

KEYWORDS: Asylum; Armed Bands; International Protection; Refugee; Recognition.

Copyright: (C) 2019 CSIC. Este es un artículo de acceso abierto distribuido bajo los términos de la licencia de uso y distribución Creative Commons Reconocimiento 4.0 Internacional (CC BY 4.0).

* Este artículo emana de una investigación mayor para la cual se cuenta con una Ayuda del programa de formación de personal investigador no doctor del Gobierno Vasco. Como agradecimiento quiero hacer mención de Jorge Gerardo y María Nelly por su atenta lectura.

1 Correo electrónico: ivanabelenrues@gmail.com. ORCID iD: <https://orcid.org/0000-0002-7696-2770>. 


\section{INTRODUCCIÓN}

La presencia de pandillas ligadas fundamentalmente al narcotráfico en varios países de la región centroamericana está generando una situación de inseguridad en la que las autoridades locales no pueden proporcionar la seguridad requerida. Ante este hecho la opción adoptada por algunas de las personas afectadas es el desplazamiento, en ocasiones dentro del propio territorio nacional, en otras hacia el extranjero. En esta segunda opción, la permanencia en destino pasará por la obtención de una protección internacional a menos que pueda optar a una residencia por el proceso de extranjería. El punto central que se abordará aquí pasa por analizar las dificultades a las que se enfrentan aquellos que intentan introducirse en el procedimiento de asilo, y la consideración que desde las instituciones se tendrá sobre su desplazamiento.

Cabe recordar el contexto de desprotección que se recoge en la Convención de Ginebra y el Protocolo de Nueva York, documentos que fijan el marco para la solicitud de asilo, pero que dejan algunas casuísticas actuales fuera de su mandato, o al menos así los interpretan los Estados que deniegan solicitudes con el argumento de que no se ajustan a los acuerdos internacionales que establecen una responsabilidad de protección. Se aborda aquí uno de esos casos, el de los sujetos que solicitan asilo fruto de una salida forzada por la inseguridad y la persecución de pandillas en la región que habitan.

Se parte en primer lugar de una breve contextualización del fenómeno de las pandillas y su relación con el desplazamiento forzado, para atender en un segundo momento al tipo de desprotección contemplada desde el procedimiento de asilo. Un tercer momento se centrará en el procedimiento de asilo ante la desprotección del Estado de procedencia. Con este recorrido se pretende plantear el debate sobre el desacople entre la legislación de asilo y las situaciones actuales en un contexto muy diferente, en donde los Estados reconociendo su responsabilidad sobre la legislación original se excusan para no responder a las demandas contemporáneas de protección.

\section{CONTEXTUALIZACIÓN DEL FENÓMENO}

El grueso de las solicitudes de asilo a causa de la actuación de pandillas, proceden del denominado
"Triángulo Norte Centroamericano» (Prado 2018) compuesto por El Salvador, Guatemala y Honduras, tres de los países con las tasas de homicidios más altas del mundo sin contar con una guerra declarada: «En 2016 la tasa de homicidios por cada 100000 habitantes se situó en 81,7 en El Salvador; en 58 en Honduras, y en 27,3 en Guatemala» (Prado 2018: 214). Las dos pandillas, maras, principales son la Mara Salvatrucha y Mara 18, organizadas trasnacionalmente (Savenije 2007), y aunque tienen sus orígenes en Estados Unidos, comenzaron su actuación en Centroamérica tras haber sido muchos de sus integrantes deportados en la década de los noventa.

La situación de violencia e inseguridad con prácticas habituales de extorsión, amenazas e intimidación a la población civil por parte de las pandillas, junto con una fuerte presencia policial y de las fuerzas armadas del Estado, ha generado una situación de "paz violenta», en palabras de Ainhoa Montoya (2018) para el caso de El Salvador, en donde el periodo de posguerra civil se ha visto atravesado por un conflicto abierto aún no reconocido oficialmente como una guerra. Atendiendo a estas características se estipulaba el documento del Alto Comisionado de las Naciones Unidas para los Refugiados, ACNUR (2016a), donde establecía las «Directrices de elegibilidad para la evaluación de las necesidades de protección internacional de los solicitantes de asilo procedentes de El Salvador» en marzo de 2016. Lo mismo haría para el caso de Honduras en julio del mismo año (ACNUR 2016b) y para Guatemala en enero de 2018 (ACNUR 2018).

Fruto de estos contextos las peticiones de asilo se han multiplicado en los últimos años. Según datos del ACNUR en 2017, 130500 personas procedentes de alguno de estos tres territorios solicitaron asilo en distintos países del globo, aunque las resoluciones favorables son ínfimas en comparación con la demanda. Atendiendo al caso del Estado español, las peticiones de asilo de personas provenientes de El Salvador y Honduras ocupan el séptimo y octavo lugar respectivamente. Los demandantes procedentes de El Salvador formalizaron 1120 solicitudes de las cuales solo se resolvieron favorablemente 60 (5,35\%); para los de Honduras se cursaron 970 , de las cuales solo $30(3,09 \%)$ tuvieron un resultado favorable (CEAR 2018: 76-78).

El recrudecimiento de las situaciones en origen y la falta de acceso al asilo en destino están generando un importante debate, que compete tanto a las instituciones encargadas de otorgar la protección inter- 
nacional como a la propia conceptualización del asilo y refugio a nivel internacional. Se llega así a dos planos encontrados, al desajuste entre las aperturas internacionales y las continuidades estatales.

\section{LA POSTURA DEL ALTO COMISIONADO DE LAS NACIONES UNIDAS PARA LOS REFUGIADOS}

Aunque el derecho de asilo por motivos de género ha sido apoyado por mandato del ACNUR, como bien nos recordaba Carmen Miguel Juan (2016) son los Estados los que mantienen la persecución política y deniegan las solicitudes de asilo por este motivo. En el caso de la persecución causada por las pandillas nos encontramos ahora con una situación similar.

Las causas que originan en estos casos la persecución no provienen de un agente estatal ni se apoyan sobre los motivos específicos recogidos en la Convención de Ginebra de 1951 que reconoce como refugiado a todo sujeto que pruebe "fundados temores de ser perseguida por motivos de raza, religión, nacionalidad, pertenencia a determinado grupo social $u$ opiniones políticas, se encuentre fuera del país de su nacionalidad y no pueda o, a causa de dichos temores, no quiera acogerse a la protección de tal país» (art. 1, apartado 2).

Tanto en los casos de desprotección por motivos de género como en los casos de desprotección del Estado ante la extorsión de las pandillas, el abordaje desde el derecho de asilo se sustenta sobre la conceptualización del término «grupo social» que ACNUR (2010: 14) entiende como: «Grupo de personas que comparte una característica común distinta al hecho de ser perseguidas o que son percibidas a menudo como grupo por la sociedad. La característica será innata e inmutable, o fundamental de la identidad, la conciencia o el ejercicio de los derechos humanos». Dentro de esta caracterización de "grupo social», las orientaciones del ACNUR son claras respecto al reconocimiento de una protección para las personas que sufren estas situaciones, no obstante, los obstáculos siguen plasmándose en el seno de los Estados.

Dado que la persecución no proviene de órganos del Estado, los solicitantes han de demostrar la omisión de ayuda por parte de las entidades públicas; una desprotección por inacción del organismo encargado de velar por la seguridad de los ciudadanos. Desde esta orientación general desarrollada por el ACNUR, la puesta en práctica derivará en lo concreto de los Estados, quedando en ellos la evaluación de la solicitud y la consideración de la desprotección como probada.

\section{ABRIENDO EL DEBATE: EL PROCEDIMIENTO DE ASILO ANTE LA DESPROTECCIÓN DEL ESTADO DE PROCEDENCIA}

El procedimiento de asilo se presenta como la forma de gestionar las solicitudes de protección, bajo la premisa de una economía moral, que como recuerda Didier Fassin (2015) coloca la preocupación por la vida como máxima de protección. La lógica del procedimiento pondrá así énfasis en la inseguridad sobre el ejercicio del «derecho a la vida», la «biolegitimidad» (Fassin 2010), convertido este en el principal de los Derechos Humanos. El procedimiento moviliza de este modo un mecanismo de reconocimiento de un sujeto que explicita la necesidad de protección, «apareciendo" (Butler y Athanasiou 2017) dentro de las instancias de gestión del asilo, al tiempo que ha de demostrar con pruebas físicas (relato, documentos, informes médicos) la situación de desprotección que sufría en origen (Fassin 2013). El trámite de asilo propiamente dicho es como se denomina al periodo que se inicia desde la presentación de la solicitud de una protección internacional hasta la resolución de la misma. Durante ese tiempo en el que el Estado estudia la petición, el solicitante no puede ser expulsado quedando a la espera de una resolución definitiva sobre su condición.

El desajuste entre las directrices internacionales y la aplicación de las mismas dentro de las fronteras de los Estados surge cuando estos últimos interpretan que las solicitudes de protección no se ajustan a ninguno de los motivos de persecución recogidos en la Convención. Dentro de las orientaciones del ACNUR se apuesta por considerar la pertenencia a un «grupo social», no obstante, los Estados continúan reticentes y argumentan que los contextos de partida son situaciones ajenas a la responsabilidad de protección que emana de un conflicto declarado o de una persecución política, esto es, deniegan la protección al mantener que en los Estados de procedencia sí se está trabajando en vías de protección a la ciudadanía. Esta postura invalida la posibilidad de contemplar a los solicitantes de asilo como sujetos de protección, e ignora la falta de efectividad que han tenido esas medidas de seguridad en las casuísticas concretas que se justifican en la solicitud. 
Los Estados, desde el diseño de su soberanía, se encuentran legitimados para la toma de decisión sobre los sujetos que contemple como posibles merecedores de protección desde este punto las disposiciones internacionales se ven plasmadas dentro de su jurisdicción como mandato vinculante, no obstante, es en la ejecución de ese mandato a nivel estatal en donde se produce el desajuste que lleva a que la economía moral, aun sin desligarse de la base de la responsabilidad de protección, se encuentre con matices que dejan fuera a un grueso de la población solicitante de asilo.

\section{CONCLUSIONES}

Los nuevos tipos de desprotección han puesto en evidencia un procedimiento de asilo que solo se activa para atender principalmente a un tipo de persecución política muy concreta y deja fuera un número cada vez mayor de casuísticas. Esta complejidad reclama una modificación de la práctica del ordenamiento jurídico (Estepa 2017) en relación con el asilo. Desde las directrices internacionales las consideraciones sobre la desprotección se han ampliado, no obstante, el debate al interior de los Estados continúa existiendo, apoyándose en su facultad para legitimar a un sujeto como demandante de asilo o dejarlo al margen del mismo. El principal debate que se abre aquí es ¿cómo articular la responsabilidad del Estado rompiendo con la disparidad entre la normativa internacional y la aplicación estatal?, ¿en qué posición se encuentra el solicitante de asilo?

Si desde las disposiciones internacionales se ha encontrado el mecanismo de incluir esas realidades que estaban apareciendo como sintomáticas de un nuevo tipo de desprotección, cabe ahora implementar en el interior de los Estados estas mismas directrices. Se trata por tanto de abrir la propia concepción del sujeto objeto de protección que permita al solicitante no ya solo amoldarse a los mandatos específicos del procedimiento, sino que también el propio procedimiento tenga en cuenta las particularidades de las que se recubre la desprotección. El Estado de origen de los solicitantes de asilo ha de ser concebido por tanto, ya no solo desde el carácter activo en la persecución, sino que cada vez más habrá de primarse la inacción y la no provisión de unas estructuras mínimas de seguridad. Se plantea, pues, la necesidad de señalar al propio Estado de origen como una estructura incapaz de tutelar a su población. El proce- dimiento de asilo ha de ser, por tanto, el mecanismo que ha de adecuarse a la actual coyuntura de la desprotección.

\section{BIBLIOGRAFÍA CITADA}

ACNUR. 1951. Convención sobre el Estatuto de los Refugiados. Disponible en: <http://www.acnur.org/fileadmin/Documentos/BDL/2001/0005.pdf>. Fecha de acceso: 7 ago. 2018.

ACNUR. 2010. Nota de orientación sobre las solicitudes de la condición de refugiado relacionadas con las víctimas de pandillas organizadas. Disponible en: <http://www.acnur. org/fileadmin/Documentos/BDL/2010/7786.pdf>. Fecha de acceso: 7 ago. 2018.

ACNUR. 2016a. Directrices de elegibilidad para la evaluación de las necesidades de protección internacional de los solicitantes de asilo procedentes de El Salvador. Disponible en: <http:// www.acnur.org/fileadmin/Documentos/BDL/2016/10786. pdf?file=fileadmin/Documentos/BDL/2016/10786>. Fecha de acceso: 7 ago. 2018.

ACNUR. 2016b. Directrices de elegibilidad para la evaluación de las necesidades de protección internacional de los solicitantes de asilo procedentes de Honduras. Disponible en: <http:// www.acnur.org/fileadmin/Documentos/BDL/2017/11033. pdf?file=fileadmin/Documentos/BDL/2017/11033>. Fecha de acceso: 7 ago. 2018.

ACNUR. 2018. Directrices de elegibilidad para la evaluación de las necesidades de protección internacional de los solicitantes de asilo procedentes de Guatemala. Disponible en: <http:// www.acnur.org/fileadmin/Documentos/BDL/2018/11658. pdf?file=fileadmin/Documentos/BDL/2018/11658>. Fecha de acceso: 7 ago. 2018.

Butler, Judith y Athena Athanasiou. 2017. Desposesión: lo performativo en lo político. Buenos Aires: Eterna Cadencia Editora.

CEAR. 2018. Informe 2018: Las personas refugiadas en España y Europa. Madrid: Comisión Española de Ayuda al Refugiado, CEAR.

Estepa Montero, Manuel. 2017. «El Derecho de asilo en España: estudio jurisprudencial sobre su posible otorgamiento a los perseguidos por "las maras centroamericanas"». Anuario Jurídico y Económico Escurialense 50: 59-76.

Fassin, Didier. 2010. «El irresistible ascenso del derecho a la vida. Razón humanitaria y justicia social». Revista de Antropología Social 19: 191-204.

Fassin, Didier. 2013. «The Precarious Truth of Asylum». Public Culture 25: 39-63.

Fassin, Didier. 2015. "La economía moral del asilo. Reflexiones críticas sobre la "crisis de los refugiados" de 2015 en Europa». Revista de Dialectología y Tradiciones Populares 70(2): 277-290.

Miguel Juan, Carmen. 2016. Refugiadas. Una mirada feminista al Derecho Internacional. Madrid: Catarata. 
Montoya, Ainhoa. 2018. The Violence of Democracy: Political Life in Post-War El Salvador. Londres: Palgrave Macmillan.

Prado Pérez, Elizabeth. 2018. «El entramado de violencias en el Triángulo Norte Centroamericano y las maras». Sociológica 93: 213-246.
Savenije, Wim. 2007. «Las pandillas trasnacionales o «maras» violencia urbana en Centroamérica». Foro internacional 189: 637-659. 